NBER WORKING PAPER SERIES

OPTING FOR FAMILIES:

RECENT TRENDS IN THE FERTILITY OF HIGHLY EDUCATED WOMEN

\author{
Qingyan Shang \\ Bruce A. Weinberg \\ Working Paper 15074 \\ http://www.nber.org/papers/w15074
}
NATIONAL BUREAU OF ECONOMIC RESEARCH
1050 Massachusetts Avenue
Cambridge, MA 02138

June 2009

We are grateful for extensive discussions with Larry Katz and Claudia Goldin. We naturally take responsibility for all errors. The views expressed herein are those of the author(s) and do not necessarily reflect the views of the National Bureau of Economic Research.

NBER working papers are circulated for discussion and comment purposes. They have not been peerreviewed or been subject to the review by the NBER Board of Directors that accompanies official NBER publications.

(C) 2009 by Qingyan Shang and Bruce A. Weinberg. All rights reserved. Short sections of text, not to exceed two paragraphs, may be quoted without explicit permission provided that full credit, including (C) notice, is given to the source. 
Opting For Families: Recent Trends in the Fertility of Highly Educated Women

Qingyan Shang and Bruce A. Weinberg

NBER Working Paper No. 15074

June 2009

JEL No. J13,J16,J22

\begin{abstract}
$\underline{\text { ABSTRACT }}$
Observers have argued about whether highly-educated women are opting out of their careers and for families. If so, it is natural to expect fertility to increase and, insofar as children are associated with lower employment, further declines in employment. This paper provides a comprehensive study of recent trends in the fertility of college-graduate women. We study fertility at a range of ages; consider both the intensive and extensive margins, explore a range of data sets; and study the period from 1940 to 2006. In contrast to most existing work, we find that college graduate women are indeed opting for families. Fertility increases at almost all ages along both the intensive and extensive margins since the late 1990s or 2000 and this recent increase in fertility is consistent across datasets.
\end{abstract}

\author{
Qingyan Shang \\ Department of Economics \\ University at Buffalo \\ State University of New York \\ 415 Fronczak Hall \\ Buffalo, NY 14260 \\ qshang2@buffalo.edu \\ Bruce A. Weinberg \\ Department of Economics \\ Ohio State University \\ 410 Arps Hall \\ 1945 North High Street \\ Columbus, $\mathrm{OH} 43210$ \\ and NBER \\ weinberg.27@osu.edu
}




\section{Opting For Families: Recent Trends in the Fertility of Highly Educated Women}

\section{Introduction}

A number of high-profile reports have indicated that after years of reducing their fertility and increasing their employment, highly-educated women are increasingly opting out of careers (Belkin [2003], Wallis [2004], Story [2005], Stone [2008]). In contrast to the popular accounts, the scholarly literature on opting out is small and generally casts doubt on the opting out phenomenon. Although the popular and scholarly work on opting out tend to differ in both size and conclusions, they line up more closely when it comes to focus, with both emphasizing changes in women's employment. ${ }^{1}$ If women are opting for families over careers, it would be natural to expect an increase in fertility. And, insofar as childbirth is associated with a reduction in employment, at least in the short run, an increase in fertility may foreshadow weaker labor attachment conditional on fertility in the future.

This paper deviates from most existing work in focusing on fertility. We provide a comprehensive study of highly-educated women's fertility. Our results demonstrate that college graduate women are opting for families, with fertility increasing among collegegraduate women at almost all ages and along both intensive and extensive margins since the late 1990s or 2000. Whether the increase in fertility we observe is associated with a reduction in employment (opting out of careers) or an increased burden on women is an important question, one that we leave for future work.

Figure 1 summarizes the main trends in the data parsimoniously, showing the

\footnotetext{
${ }^{1}$ As discussed below, a number of researchers have studied the child employment gap or penalty, the gap in employment between women with and without children.
} 
average number of children born to college graduate women from different birth cohorts at a range of ages (this measure combines intensive and extensive margins, which are separated out below). The longer series, based on Census and Current Population Surveys (CPS), shows 3 major shifts. The first shift is a large increase in fertility from the low levels of the cohorts born at the end of the $19^{\text {th }}$ and the beginning of the $20^{\text {th }}$ century through the cohorts born in the 1930s. This increase in fertility corresponds to the baby boom and is in keeping with Goldin [1997], who argues that until 1941, marriage bars limited the ability of college women to have both children and careers. The second major shift is a dramatic decline and delay in fertility, which runs through the birth cohorts born in the 1950s and 1960s. This decline in fertility erases a large portion of the earlier increase, especially at younger ages, reflecting delayed fertility. ${ }^{2}$ The third shift begins with the cohorts born in the 1950s and 1960s. Here fertility flattens out and, beginning in the late 1990s or 2000, increases. Estimates from the Vital Statistics Birth Data merged into the CPS, which cover the more recent years, are quite close to those from the Census and CPS and show generally similar trends, including the recent increase in fertility. Placed in the context of the long-term trends, it is clear that the recent increase in fertility is small, but it holds across age groups.

We are aware of two studies that include estimates of recent trends in fertility of highly-skilled women (along with a range of other outcomes). ${ }^{3}$ Both studies, while

\footnotetext{
${ }^{2}$ Delayed fertility can also be seen by noting that the flat portion of the lowest curve (for women who are between 25 and 29) is at roughly the same level as that of the first cohorts (or years), but the flat portions of the other series are at higher levels than that of the first cohorts (or years). Thus, early-life fertility has been quite low, with much of the increase in fertility from the early cohorts (or years) until today stemming from a shift to fertility in the 30s.

${ }^{3}$ More loosely related to the current work, Abma and Martinez [2006] study voluntary versus involuntary childlessness, showing a decline in voluntary childlessness between 1995 and 2002. Their results cover all
} 
valuable, have limitations and ironically they come to opposite conclusions. Vere [2007] studies mean cumulative fertility (or the number of children born) focusing on 27 year old college-educated women between 1982 and 2002. He finds an increase in fertility for this group, but 27 is early in the childbearing years, especially for college-educated women. Changes in fertility in the 20s may say more about the timing of fertility than completed fertility, with fertility later in life partially or fully offseting these early-life trends.

The only other studies to consider the fertility aspect of opting out, Percheski [2008], finds no increases in fertility among professional women. Her sample of women in professional or managerial occupations, has the advantage of pinpointing women in high-powered careers, but makes her results somewhat hard to interpret because women who have more children or choose to reduce their hours may switch to less intense occupations. (Our analysis, like most, addresses this concern by defining the sample using education which, while affected by expectations over employment, will be much less responsive to short-term decisions.)

As indicated, there is somewhat more work on the employment aspect of opting out. Boushey [2005] studies trends in the labor force participation among women in their childbearing years (between age 25 and 44). She argues that declines in women's employment between 2000 and 2004 are due to business cycle effects. She also studies the child-penalty - the gap in labor force participation between women with and without young children - finding that it has declined in recent years. Cohany and Sok [2007] find that the labor force participation rate of highly educated married mothers declined in the 
late 1990s, but was stable between 2000 and 2005. They argue that the trends among this group are similar to those for less-educated married women. Percheski [2008] also finds no evidence of a decline in the labor force participation rates and rates of full-time, fullyear work among professional women. Like Bouchey, she finds that the child-penalty has, if anything, declined among professional women. Only Vere, looking at 27-year olds finds employment evidence for opting out.

A third line of work studies specialized samples of graduate alumni from elite institutions. Bertrand, Goldin, and Katz [2009] study MBAs graduates from the University of Chicago's Booth School of Business, finding that career interruptions from childbirth are responsible for most of the earnings gap among men and women. Using alumnae from Harvard University, Herr and Wolfram [2009] find that the family friendliness of jobs is an important determinant of women's employment decisions.

The present paper is considerably more comprehensive than the relatively small and contradictory work on recent trends in fertility among highly educated women in a number of ways. We study fertility at a range of ages from the 20s through the 40s; we consider both the intensive and extensive margins, including the mean number of children born, childlessness, and the distribution of the number of children; we estimate fertility from a variety of data sets including the Census, CPS, and Vital Statistics Birth Data (matched to the CPS); and our data covers a considerably longer time span than existing studies - from 1940 through 2006.

We find clear evidence of an increase in fertility that is specific to highly educated women since the late 1990s or 2000. Although not directly related to opting out, we also find a dramatic increase in plural births, especially among older women. We take 
this increase in plural births as evidence of fertility treatment.

Interestingly, our estimates of the distribution of children born may help to explain others' results. For instance, we find a decrease in women with no children in recent years. If more women with strong labor market attachment are now having children, as they have more children, the difference in employment between women with and without children may drop even if it is increasing for any given woman.

\section{Data}

Two major data sources are used in this paper to study the fertility patterns of college graduate women: the decennial Censuses extended with the Fertility Supplement to the June Current Population Survey (CPS) and the Vital Statistics Birth Data from the National Center for Health Statistics combined with population data from the March CPS.

We use the $1 \%$ samples of the 1940-2000 Censuses. We focus on women with 16 or more years of school. ${ }^{4}$ The $1940-90$ Censuses ask women about "the number of children ever born." ${ }^{5}$ Unfortunately, "the presence and age of own children” is the only fertility variable in the 2000 Census. Thus it is not possible to estimate the number of children born for women in their 40s because as children move out of the house, childlessness is overstated.

We use the Fertility Supplement to the June CPS to extend the Census-based

\footnotetext{
${ }^{4}$ The definition of educational attainment in the 1990 and 2000 Censuses and the CPS in and after 1992 is based on the highest degree attained instead of the number years of school as in earlier surveys. Along with the March CPS and the Vital Statistics (discussed below) data, the degree-based classification was converted back to one based on years of completed schooling by weighting births by women with a college degree or higher on the new certificates by 1.007599 based on Jaeger [1997].

${ }^{5}$ In the 1940-60 Censuses, only ever-married females were asked the fertility question. Beginning with 1970 Census, all females aged 14 or above were asked the fertility question.
} 
analysis to the most recent years. The June CPS asked women aged 14 to 44 how many

children they had ever had, which is very similar to the fertility question in the 1940-90

Censuses, providing a useful alternative to the 2000 Census. One (relatively modest)

disadvantage of these data is that they only provide fertility information on women

through age 44, complicating comparisons with the Census. They also provide

considerably smaller samples, which becomes relevant as we focus on relatively narrow

groups. The latest release of the Fertility Supplement is the 2006 June CPS. ${ }^{6}$

For any given year, the estimates reported below are for cells that combine

multiple birth years or years of age. To control for changes in the age distribution of the

population within each cell, we first construct means for individual birth years or years of age and then average these within each cell.

We also use the 1976-2006 Vital Statistic Birth Data to estimate the number of births. The Vital Statistics are based on information abstracted from birth certificates, and include all births occurring in a given calendar year within the United States to U.S. residents and nonresidents. ${ }^{7}$ This section outlines the primary features of our approach. A detailed discussion is in the Data Appendix.

Our birth sample includes births to mothers with 16 or more years of school.

Before 1992, not all states report mother’s educational attainment. ${ }^{8}$ We obtain national

\footnotetext{
${ }^{6}$ Another difference between Census Sample and Birth sample is that the education data in the Vital Statistics is the education attained at the time of the birth of a child. Education data in CPS or Census measures education attained at the time of interview.

${ }^{7}$ Before 1985, only 50\% samples are available for some states. Data from these states in these years are weighted to produce nationally-representative statistics.

${ }^{8}$ Schooling data is not available for all parts of Arkansas, California, Idaho, New York State, Texas, Washington State, and New Mexico in at least some years. In addition, before 1988, mother education is missing for more than $7 \%$ of the observations in a small number of states that report mother's schooling. As explained in the data appendix, we re-weight our Vital Statistics Birth Data by age and live birth order
} 
estimates for the years for which schooling is not available for some states by reweighting births for states with schooling data to make them nationally representative.

To construct birth rates from the birth counts, the birth counts were merged into data on the population of women constructed from the 1976-2006 March CPS. We estimate fertility by age and parity, focusing on college graduate women, although similar methods could be applied to multiple education groups. For simplicity, we suppress education indicators here. Let $n_{\text {tap }}$ denote the number of children born in year $t$ to women at age $a$ and parity $p-1$, that is, who have had $p-1$ live births before the current birth. Let $N_{t a}$ denote the population of women in year $t$ at age $a$. In year $t$, the share of women at age $a$ who are having their $p^{\text {th }}$ child is $s_{\text {tap }} \equiv \frac{n_{\text {tap }}}{N_{t a}}$. This constitutes a flow of parity $p$ births to age $a$ women. Let $S_{\text {tap }}$ denote the share of women at age $a$ who, at the end of year $t$, have had $p$ children. This variable constitutes the stock of women at given parities. We construct $\left\{S_{\text {tap }}\right\}_{p \in\{0,1,2,3,4+\}}$ from $\left\{S_{t-1, a p}\right\}_{p \in\{0,1,2,3,4+\}}$ and $\left\{S_{\text {tap }}\right\}_{p \in\{0,1,2,3,4+\}}$ according to $S_{\text {tap }}=S_{t-1 a p}+S_{\text {tap }}-S_{\text {tap }+1}$. That is, we start with the stock of women who have $p$ children at the beginning of $t$ (at the end of $t-1$ ) and add in the flow of women having their $p^{\text {th }}$ child in year $t$ and subtract out the flow of women having their $\left(p^{+1}\right)^{\text {th }}$ child in year $t$. We track college graduate women starting at age 23, obtaining the stocks at age 23 by assuming that they are equal to the shares of children born (at each parity) to 23-year old women. Formally, we assume $\left\{S_{t, 23, p}=s_{t, 23, p}\right\}_{p \in\{0,1,2,3,4+\}}$. Evidence on the 
plausibility of this assumption is provided in the Data Appendix.

A natural concern with our procedure arises for women completing college after age 23. To address this concern, we convert all variables to shares of the population before constructing the stock variables from the flow variables. This procedure implicitly uses the distribution of the number of children among women who had already completed college by a given age to impute the distribution among women completing college at that age. (A procedure that generates stocks from flows first and then converts them to population shares implicitly assumes that women having children at later ages have not had any children. Estimates from the two procedures are broadly similar.) A variety of other potential biases are also discussed in the data appendix.

Figure 1 (discussed above) reports the average number of children born by women by varying ages using the Vital Statistics. These estimates are the cumulative sum of the age-specific birth rates (of all parities) from age 23 till that age. This procedure is similar to Vere [2007].

\section{Results}

\section{Long-Term Trends}

Table 1 reports childlessness and the share of women who had never been married for 10-year birth cohorts. Figure 2 plots childlessness by age for 5-year birth cohorts from the 1940 to 1990 Censuses and the 2000, 2004 and 2006 CPS. ${ }^{9}$ It also shows estimates from the Vital Statistics Birth Data merged into the CPS for the most recent years. The census shows that in 1940 (the first observation for each age group in the

\footnotetext{
${ }^{9}$ There was no Fertility Supplement to the 2005 June CPS. The 2006 June CPS is the most recent available fertility supplement. In this figure and Figure 1, the last point for each age group is the average of 2004 and 2006. Here the ages shown are approximate in that we track cohorts, so that women will be 1 year younger
} 
table), fertility and marriage rates were low for college women of all ages. Family

formation increased from the 1940s through the 1960s, but this change was not

experienced uniformly by all birth cohorts. By the time the second cohort, born in 1901-

10 , was in their 40 s, marriage rates had increased compared with the first cohort, but

childless rate remained high. ${ }^{10}$ Fertility and marriage increased for the 1911-20 cohort,

which was between 20 and 29 in 1940. By 1960, when they were in their 40s, their

marriage rate and fertility rate were substantially higher than that of the first two cohorts.

The increase in fertility was underway by the time the next two cohorts entered their

childbearing years, and both their marriage and family formation were substantially

higher compared to earlier cohorts. Thus, the share of women in their 20s (22-29) who

have never been married falls in half between the 1911-20 and 1931-40 cohorts from

$59.8 \%$ to $30.0 \%$ and the share without children declines by close to $30 \%$ from $82.2 \%$ to

55.2\%. By 1980, when the 1931-40 cohort was in their 40s, only $18.6 \%$ were childless

and only $7.9 \%$ had never married.

The 1960s constitute a second shift, especially for the younger cohorts. ${ }^{11}$

Although marriage rates in the 20s for the 1941-50 cohort were as high as for the 1931-

40 cohort, their fertility was lower. The 1941-50 cohort begins a trend not only toward

lower fertility, but also to delayed fertility, which becomes stronger among later cohorts.

\footnotetext{
than shown in the 2004 CPS and one year older in the 2006 CPS.

${ }^{10}$ Childlessness did not decline even though marriage rates increased because among ever-married women between 40 and 49, childlessness increased from 21.5\% for the 1891-1900 cohort to 27.3\% for 1901-10 cohort.

${ }^{11}$ Goldin and Katz [2002] and Bailey [2006, Forthcoming] both emphasize the importance of the birth control pill, but others have emphasized changes in family income and women's wages (e.g. Becker [1991]). The 1921-30 cohort had almost completed their fertility by 1970. The 1931-40 cohort was between 30 and 39 in 1970. Childlessness was already very low for this group, but only decreased by $4.3 \%$ in the next 10 years.
} 
The delay in fertility is visible at early ages, when childlessness begins to increase from $55.2 \%$ for the $1931-40$ cohort to about $83 \%$ for the $1961-70$ and $1971-80$ cohorts.

Completed fertility also decreases, but substantially less, with childlessness in the 40s increasing and then stabilizing at around 25\% for the 1941-50 cohort and the ones that followed. ${ }^{12}$ Our calculations show that the mean number of children declined by more than half a child from the 1921-30 and 1931-40 cohorts to roughly 1.6 children (unconditional on having a child) or 2.15-2.25 children (conditional on having a child) for the 1941-50 cohort. (We discuss trends in mean fertility for the more recent cohorts below.)

Looking at the period as a whole (from the 1911-20 cohort and even more the 1891-1900 cohort through the 1961-70 cohort), shows that the trend to fewer children after the 1931-40 cohort completely reversed the earlier increase in fertility among women in their 20s, but that the reversal has been smaller at older ages. Thus, the period as a whole shows the postponement of childbearing, more than an increase in childlessness (by the 40s).

In the most recent years, the 1971-80 cohort delayed marriage and fertility in their 20s just as the 1961-70 cohort did, however, in their 30s in 2006, the 1971-80 cohort had a much lower rate of childlessness compared with the 1961-70 cohort. Figure 2, which breaks the Census and CPS data into 5-year cohorts and shows data from Vital Statistics, shows that this trend toward increased fertility holds across all age groups. The decline in

\footnotetext{
${ }^{12}$ It is worth noting that the stability that we find for the 1951-60 and 1961-70 cohorts between 2000 and 2006 is only for women aged 40-44 from these cohorts. By contrast, fertility increases among the younger portion of the 1961-70 cohort (aged 36-40 in 2006). This increase constitutes a break from the previous trend to lower fertility and will be visible when we look at 5-year birth cohorts in Figure 2 and Table 2 below.
} 
childlessness is larger in the Vital Statistics at older ages and larger in the Census / CPS at younger ages but despite these differences, the two series track one another and, taken together, show a decline in childlessness in recent years at all ages.

This decline in childlessness constitutes a break in the long-term trend toward lower and delayed fertility since the 1941-50 cohort, although it is impossible to extrapolate to the completed fertility of the younger cohorts (e.g. the 1971-80 cohort). The timing corresponds to the media reports of college women opting out of labor market. We will next look at recent trends in the fertility of college women in detail.

\section{Recent Trends}

Table 2 plots childlessness for college women of various age groups since 1980. We focus on 5-year age groups here and augment the Census results with data from the Fertility Supplement to the June CPS to obtain data every 5 years and to bring the data forward to 2004 / 2006. As indicated, estimates from the CPS are considerably noisier than those from the Census because of the smaller samples, but they have an important advantage over the 2000 Census in that they ask about children ever born rather than children living at home, facilitating comparisons for older women.

In keeping with Table 1, fertility declined between 1980 and 1990. Between 1990 and 2000, childlessness increases slightly among women in their late 20s, but it decreases slightly among older women. This decrease continues after 2000, affecting all age groups, but it is particularly strong for younger women.

Although childlessness of women aged 25-29 increases until 2000, it decreases by at least 4\% between 2000 and 2004/6. For women aged 30-34, childlessness is noticeably lower in 2006 (and the average of 2004/6) than in 2000, but the rates of childlessness are 
comparable for these two cohorts of women at ages 25-29 (in 1995 and 2000

respectively). Similarly, childlessness among women ages 35-39 is lower in 2004/6 than in 2000, but childlessness was slightly higher for the later of these cohorts up to and in their early 30s (in 1995 and 2000 respectively). The most recent cohort for which data is available at ages 40-44 (the one that is 40-44 in 2004/6) shows lower childlessness than the cohort before it from age 25-39, but at age 40-44 there is no difference in completed fertility. Thus, the recent decline in childlessness is widespread with the possible exception of this last cohort.

Table 3 shows trends in the mean number of children born tracking cohorts in the Census and CPS. Cumulative fertility increases over the life-cycle. There are also systematic changes across cohorts. The table shows a clear trend toward lower fertility at early ages, with fertility declining at ages 25-29 from .419 children for the 1951-55 to .318 children for the 1971-75 cohort. There is also a clear trend toward increasing fertility at later ages, with fertility rising from 1.399 to 1.486 at ages 35-39 and from 1.550 to 1.612 at ages $40-44$, with each cohort having higher fertility than the cohorts before it. Thus, the reduction in fertility in the late 20s after the 1951-55 cohort (which itself had lower fertility at both younger and older ages than the cohorts before it) reflects a delay in fertility and not a reduction in completed fertility. The trend toward lower fertility reverses dramatically at ages 25-29 for the 1976-80 cohort, from roughly .32 for the 1966-70 and 1971-75 cohorts to .390. Indeed the table shows that fertility increased more at all ages (other than 40-44) between 2000 and 2004/6 than in any previous period.

Figure 3 makes these points visually. It shows the difference in mean fertility between the 1951-55 cohort and each successive cohort at various ages. The reduction in 
fertility at young ages after the 1951-55 cohort can be seen from the negative values for the late 20s. The graph also shows the increase in fertility at later ages, with all points for the 30 s and 40 s lying above 0 . The progressive nature of this change is visible in that the curve for each group is pivoted counterclockwise from the curve for the group(s) that precede it. The figure also shows the dramatic reversal of the trend toward lower fertility among 25-29 year olds in the 1976-80 cohort, with this point lying well above all others. This increase in fertility can be seen in all cohorts in that at all ages the last point (from to the 2004/6 CPS) shows the largest increase from the 1951-55 cohort and the gaps between the last (2004/6) and next to last points (2000) for each cohort are among the largest.

The composition of college graduates has changed considerably over time, with the share who are native-born, non-Hispanic, and white declining. Changes in the immigrant population or the racial or ethnic composition of the population may affect these estimates. To ensure that our estimates are not due to changes in the composition of college-graduates, and to probe the statistical significance of these estimates Appendix Table 1 reports regression-based estimates. The model is

$$
\text { Childless }_{i t}=X_{i t} \beta+\text { Year }_{t} \Gamma+\varepsilon_{i t} .
$$

Here Childless ${ }_{i t}$ indicates if woman $i$ in year $t$ is childless; $X_{i t}$ denotes the characteristics of woman $i$ in year $t$; and $Y e a r_{t}$ denotes a set of year dummy variables, which provide the time trends that are of interest. The omitted year in all the estimates is 1995. The characteristics include a linear schooling effect (to capture variations in schooling among college graduates) and dummy variables for individual years of age (within the age 
groups), race (black or other), and Hispanic background. ${ }^{13}$

The first column reports time trends, the estimated coefficients on the year dummy variables for all women between ages 25 and 44. They show an increase in childlessness between 1980 and 1995 and then a decrease in childlessness in the following years. This decline is large and statistically significant, building over time. The remaining columns report separate estimates for the 4 age groups. They all show an increase in childlessness until 1995 and then a decline. The estimated decline is statistically significant for all age groups except the 40-44 group. Controlling for the characteristics of college-graduate women does not have a large impact on the trends (in part because even in 2006, over $70 \%$ of college graduate women were native-born, nonHispanic whites).

\section{Decomposing Recent Trends}

Changes in marital status are likely to affect fertility and the fertility of ever married and never married women may change differently. Table 4 shows trends in marital status and trends in childlessness among ever married and never married women. The top panel shows that the share of women who have never been married has increase over time among women aged 25-29 and 40-44, but that it has been fairly stable among women in their 30s since 1990. The second panel shows that although childlessness among never-married, college graduate women is quite high (always above 85\%), it has decreased substantially since its peak in the mid to late 1980s. Among women aged 2529, the share with children more than triples from roughly 2.5\% in 1980 and 1985 to 9\%

\footnotetext{
${ }^{13}$ We did not control for marital status because it might be endogenous, but we stratify by marital status below.
} 
in 2006. The changes in the other age groups are similar in absolute magnitude although smaller in percentage terms. Ever-married women also show declines in childlessness, but these declines start later - in the early to mid 1990s - and are smaller. Because changes in the share of women who have never been married are small and vary across groups, most of the recent decline in childlessness is due to declines within the ever married and never married groups. However, the contribution of changes among nevermarried women is greatest at young ages, where a larger share of women have never been married.

\section{Other Groups}

It is possible that recent increases in fertility among college-graduate women are part of a larger trend toward greater fertility. To address this question, we study trends in fertility at a variety of education levels. Table 5 shows that the large decline in childlessness for college women during 2000-2006 did not hold across education groups. While the estimates show some variations, among women who are (exactly) high school graduates, childlessness increased between 2000 and 2004/6 for most age groups. The estimates for women with some college do not show a strong trend. By contrast, all the figures for women with graduate education show declines between 2000 and 2004/6. Thus, the trend toward higher fertility is greatest among highly-educated women.

\section{Birth Distribution}

It is natural to consider whether fertility increased along the intensive margin as well as the extensive margin. If women who are already having children increase the number of children they have then fertility increases along the intensive margin. In studying changes in fertility along the intensive margin, it is worth bearing in mind that 
as more women have children, if the marginal mothers tend to have relatively few children, the mean number of children among women who have children may fall even as fertility increases among inframarginal mothers. Table 6 shows that among women who have children, the average number of children born increases in all but the oldest age groups between 2000 and 2004/6. This increase in conditional fertility for all but the oldest groups, indicates a substantial increase in fertility along the intensive margin at younger ages and perhaps an increase at older ages as well.

Figure 4 shows changes in the distribution of the number of children women have across birth cohorts at different ages from the late 20s through the early 40s. We focus on 5-year birth cohorts, with estimates for the early years coming from the census and later years from the CPS. The figures also show estimates from the Vital Statistics Birth Data.

The graph for the late 30s is a useful starting point. It shows a large decline in the share of women with no children between the 1901-05 and 1931-35 birth cohorts (in 1940 and 1970). After the 1931-35 cohort, the share of women with no children begins to increase, flattening out with the 1951-55 cohort (in 1990), and reversing at the end of the period. These are the patterns discussed above.

The changes in fertility along the extensive margin documented above are echoed along the intensive margin. The share of women with exactly one child tracks the pattern for women with no children, but with swings that are considerably smaller. (The exception is in the most recent years, when the share of women with no children declines, but the share of women with one child increases slightly.) The share of women with exactly 3 children and the share with $4+$ children are both mirror images of the share of women with no children, rising initially and then declining. In the most recent years, the 
share of college-graduate women having 3 and 4+ children, though low, have both increased.

Having exactly 2 children is, in a sense, the break point in the distribution. Among women in their late 30s, the share with exactly 2 children increases through the cohorts born in the middle of the century, then declines, increasing again in the most recent years. By the 1931-35 cohort, having 2 children is the dominant choice, and the meaning of these trends in the share of women with exactly 2 children shifts. The increase in women with exactly 2 children among the early cohorts is part of the increase in fertility, coinciding with the decline in women with no children or 1 child and the increase in women with 3 and $4+$ children. In the cohorts born in the middle of the century, the increase and then decrease in the share of women with exactly 2 children is part of the decline in fertility, coinciding with the decrease in the share of women with 3 and 4+ children and the increase in women with no children or exactly 1 child. In the most recent years, the increase in fertility is reflected in an increase in the number of women with exactly 2 children. The estimates from the Vital Statistics are similar to those from the Census and CPS in both their levels and timing.

The other panels generally echo these patterns. For natural reasons, the panels for women in their late 20s and early 30s both show considerably more women with no children and considerably fewer women with 3 and 4+ children (and correspondingly smaller shifts for these groups). Again for natural reasons, the panel for women in their early 40s, which is effectively completed fertility, shows even higher shares of women with 1, 2, 3, and 4+ children but fewer women with no children.

As in Figures 1 and 2, the Vital Statistics show higher and more stable fertility for 
the youngest women and lower and more rapidly increasing fertility for the oldest women than the Census and CPS. The Vital Statistics also show more women with 4+ children and fewer women with exactly 3 children than the Census and CPS in the late 30s and 40s. Subject to these differences, data from the two sources is generally similar in both levels and trends. This similarity is particularly true for women in their early 30s.

The delay in fertility is also evident in these figures. Starting with the 1941-45 cohort, fertility declined in the late 20s and early 30s, with the share of women with no children increasing, and the share with exactly 1 child increasing among women who had children. For women ages 30-34 the 1961-65 cohort is actually the first cohort in half a century (since the 1906-10 cohort) for which having 1 child is the leading choice among women with any children. Despite all of the increases and decreases in fertility, in their late 20s, the distribution of the number of children among the 1961-65 cohort looks remarkably similar to that of the 1911-15, born fifty years before. However, the two cohorts differ considerably at later ages, say in their early 40s, with the 1961-65 cohort being considerably more likely to have 2 children and considerably less likely to have no children than the 1911-15 cohort.

Our best estimate of completed fertility, from the Census and CPS, was relatively stable for the 1946-50 cohort through the 1962-66 cohort, but there is a slight tendency toward more children visible among the latest cohort, with the share of women having no children decreasing and the share having 1 or 2 increasing somewhat. The Vital Statistics, by contrast, show a substantial increase in fertility at older ages. Thus despite the somewhat contradictory evidence and despite the limited the scope for adjusting cumulative fertility at older ages, we find some evidence that college graduate women are 
for opting for higher fertility even at older ages.

In summary, there is evidence that fertility has increased between 2000 and 2006 more generally. Comparing these years (these are the last 2 points for the Census / CPS on each graph), at all four sets of ages, the CPS shows that the share of women with no children has decreased and, with the exception of women in their early 40s with exactly 3 children, the share of women with 1, 2, 3, and 4+ children have all increased for all four age groups. The Vital Statistics also show a clear increase in fertility, especially at older ages.

\section{Plural Births}

Figure 5 plots the share of children born to college graduate women who were born in a plural birth. ${ }^{14}$ The rate of plural births increased dramatically over time. And while it increases among all age groups, the increase is substantially greater for older women. (We are not aware of explanations for the initial decline among 40-44 year old women, although it reverses dramatically in subsequent years.) In the late 1970s, the plural birth rate was only slightly higher for older women than younger women, but they begin to spread apart around 1990. From 1976 to 2002, the plural birth rate increased by slightly more than $50 \%$ (from $2 \%$ to just over $3 \%$ ) among college women aged 23 to 29 , but among college-graduate women in their early 40s, the plural birth rate nearly triples (from under 3\% to under 8\%).

The initially higher rate of plural births among older women is consistent with physiological evidence that older women are more likely than younger women to have

\footnotetext{
14 These estimates are weighted by children, so each child in a set of twins, triplets, etc. is counted separately. Implicitly, higher-order plural births receive more weight. These results are based on the 46
} 
multiple births, but this physiological mechanism can not explain the greater increase in plural births among older women. The greater increase among older women appears to be due to greater use of fertility treatments. Martin et. al [2007] write, “These therapies include assisted reproductive technologies (ART) in which eggs and sperm are handled in the laboratory (e.g., in vitro fertilization), and non-ART therapies such as ovulationinducing drugs and artificial insemination. ART therapies alone are estimated to account for 17 percent of all twins and 40 percent of triplets born in 2004. Assisted Reproductive Technology (ART) has been used in the United States since 1981." ${ }^{\text {15 }}$ While we do not directly relate trends in plural births to opting out and there is no apparent shift in plural births since the late 1990s, fertility treatments are part of women's efforts to have families.

\section{Conclusion}

Researchers studying opting out have focused on reductions in employment conditional on fertility. If women are opting for families over careers, it is natural to think that their fertility would increase. Moreover, increases in fertility are likely to be associated with reductions in employment because women who have young children spend more time out of the labor market. This paper has provided a comprehensive study of college graduate women's fertility. Estimates from the Census and CPS and Vital Statistics Birth Data both show that college graduate women are indeed opting for higher fertility. Fertility has increased at almost all ages and along both the intensive and extensive margins since the late 1990s or 2000 and this recent increase in fertility is 
consistent across datasets.

Our finding that highly educated women are increasingly choosing not to sacrifice their families for careers raises a number of questions that we leave to future work. At a factual level - when women opt for families, are they opting out of the labor market, as has been argued in the media, are they (somehow) opting to have both families and careers?

Our finding that women are increasingly opting for families also calls for explanations. One potential explanation is a learning story, whereby higher fertility is a reaction to previous generations of women who postponed fertility and ultimate had little opportunity to have families. Another explanation involves selection - as more women have gone to college, the average college graduate woman is likely to have become less career oriented. Some such a shift may have occurred over the $20^{\text {th }}$ century as a whole, but the extent to which it can explain changes in fertility over the past decade is less clear. ${ }^{16} \mathrm{~A}$ number of researchers have pointed to the growth in personal services in recent years (Mazzolari and Ragusa [2007]; Autor and Dorn [2008]; and Cortes and Tessada [2008]). An increase in the supply of personal services would reduce the price to women of having children, allowing women to shift the burden to the market. Alternatively, Feyrer, Sacerdote, and Stern [2008] have argued that men may be taking more responsibility for child care. Lastly, the gender wage gap, which had been closing rapidly since the 1970s has since been constant, so the opportunity cost of women's time is no

\footnotetext{
${ }^{15}$ It is worth noting that the American Society of Reproductive Medicine introduced recommendations in the late 1990s, which were revised in 2004 and 2006, to prevent higher-order multiple gestations.

${ }^{16}$ Goldin [1997] casts doubt on selection as a primary explanation for earlier changes.
} 
longer increasing relative to men's time, which may have lead to an increase in fertility. ${ }^{17}$

${ }^{17}$ Blau and Kahn [2006] find essentially no convergence in the gender pay gap at high quantiles during the 1990s. 


\section{References}

Abma, Joyce C. and Gladys M. Martinez. 2006. "Childlessness among Older Women in the United States: Trends and Profiles.” Journal of Marriage and Family 68 (November): 1045-56.

Autor, David and David Dorn. 2008. “ Inequality and Specialization: The Growth of Low-Skill Service Jobs in the United States.” Working Paper.

Bailey, Martha J. 2006. "More Power to the Pill: The Impact of Contraceptive Freedom on Women's Lifecycle Labor Supply," Quarterly Journal of Economics 121 (No. 1, February): 289-320.

Bailey, Martha J. Forthcoming. "Momma's Got the Pill: How Anthony Comstock and Griswold v. Connecticut Shaped U.S. Childbearing" American Economic Review, forthcoming.

Becker, Gary S. 1991. A Treatise on the Family. Cambridge, MA: Harvard University Press.

Belkin, Lisa. 2003. “The Opt-Out Revolution.” New York Times Magazine. October 26.

Bertand, Marianne, Claudia Goldin, and Lawrence F. Katz. 2009. "Dynamics of the Gender Gap for Young Professionals in the Financial and Corporate Sectors.” Working Paper.

Blau, Francine and Lawrence M. Kahn. 2006. "The US Gender Pay Gap in the 1990s: Slowing Convergence.” Industrial and Labor Relations Review 60 (No. 1, October): 45-66.

Bouchey, Heather. 2005. “Are Women Opting Out? Debunking the Myth.” CEPR Briefing Paper.

Cohany, Sharon R. and Emy Sok. 2007. "Trends in Labor Force Participation of Married Mothers of Infants.” Monthly Labor Review (February): 9-16.

Cortes, Patricia and Jose Tessada. 2008. “Cheap Maids and Nannies: How low-Skilled Immigration is Changing the Labor Supply of High-Skilled American Women. Working Paper.

Feyrer, James; Bruce Sacerdote; and Ariel Dora Stern. "Will the Stork Return to Europe and Japan? Understanding Fertility within Developed Nations.” Journal of Economic Perspectives 22 (No. 3, Summer): 3-22.

Goldin, Claudia. 1997. "Career and Family: College Women Look to the Past.” In Gender and Family Issues in the Workplace, edited by Francine Blau and Ronald Ehrenberg. New York: Russell Sage Foundation. 
Goldin, Claudia and Lawrence F. Katz. 2002. "The Power of the Pill: Oral Contraceptives and Women's Career and Marriage Decisions.” Journal of Political Economy 110 (No. 4, Aug): 730-70.

Herr, Jane Leber and Catherine Wolfram. 2009. “’Opt-Out’ Rates at Motherhood Across High-Education Career Paths: Selection Versus Work Environments.” Working Paper.

Martin, Joyce A., Brady E. Hamilton, Paul D. Sutton, Stephanie J. Ventura, Fay Menacker, Sharon Kirmeyer, and Martha L. Munson. 2007. "Births: Final Data for 2005.” National Vital Statistics Reports 56 (No 6, Dec 5): 24-25.

Mazzolari, Francesca and Giuseppe Ragusa. 2007. "Spillovers from High-Skill Consumption to Low-Skill Labor Markets.” Working Paper.

Percheski, Christine. 2008. “Opting Out? Cohort Differences in Professional Women’s Employment Rates from 1960 to 2005.” American Sociological Review 73 (June): 497-517.

Stone, Pamela. 2008. Opting Out? Why Women Really Quit Careers and Head Home. Berkeley, CA: University of California Press.

Story, Louise. 2005. "Many Women at Elite Colleges Set Career Path to Motherhood.” New York Times. September 20.

Vere, James P. 2007. “Having it All’ No Longer: Fertility, Female Labor Supply, and the New Life Choices of Generation X.” Demography 44 (No. 4, November): 821-8.

Wallis, Claudia. 2004. “The Case for Staying at Home.” Time Magazine. March 22. 
Figure 1. Average Number of Children Born to College Graduate Women by Cohort and Age.

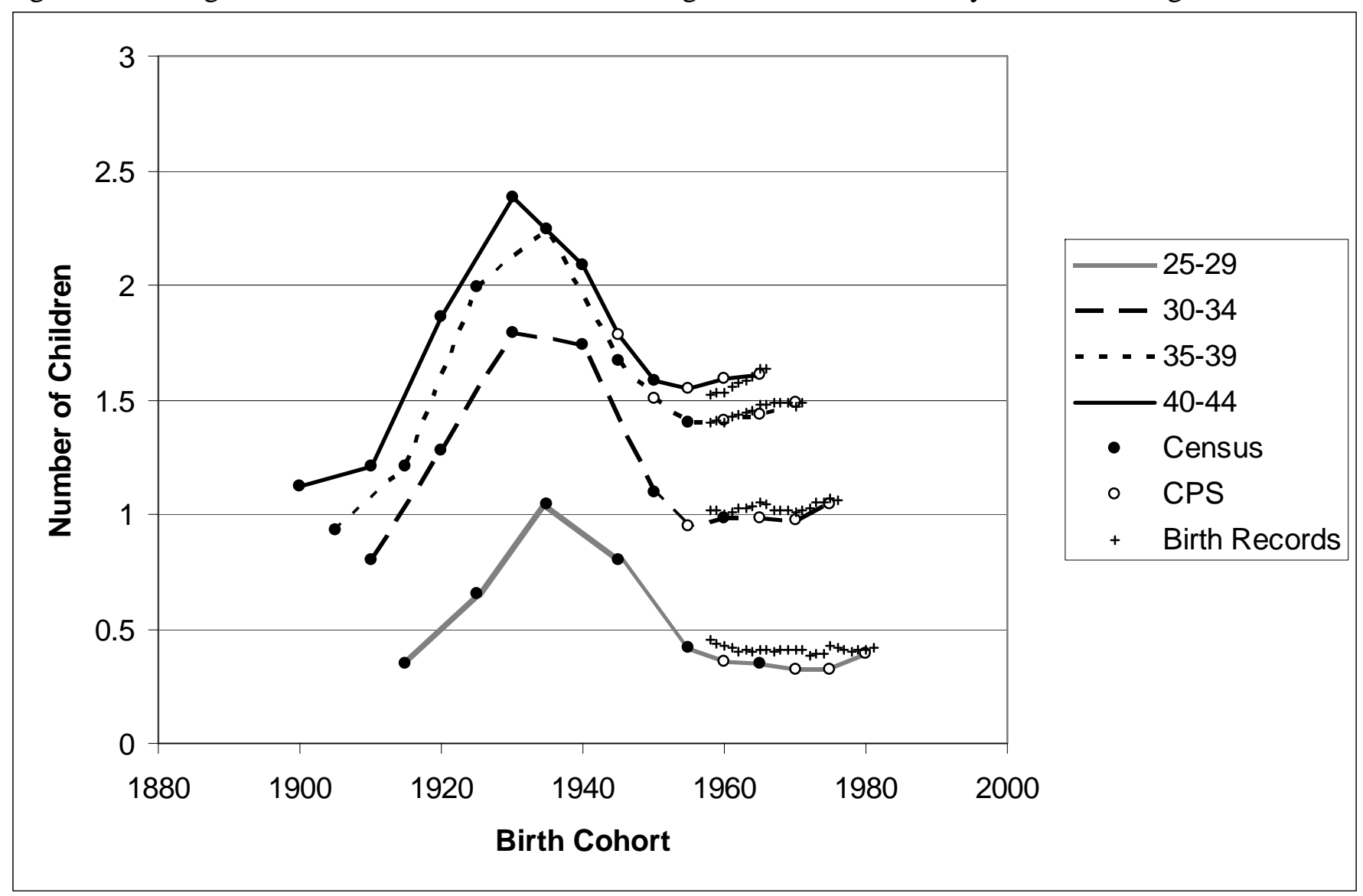

Note. Estimates for college graduate women from the 1940-90 Censuses, the 1985, 1995, 2000, 2004, and 2006 June CPS, and the 1976-2006 Vital Statistics matched to the March CPS. Estimates shown for 5-year birth cohorts, with the birth years shown, giving the birth year of the youngest members of each cohort. 
Figure 2. Childlessness Among College Graduate Woman, by Birth Cohort and Age.

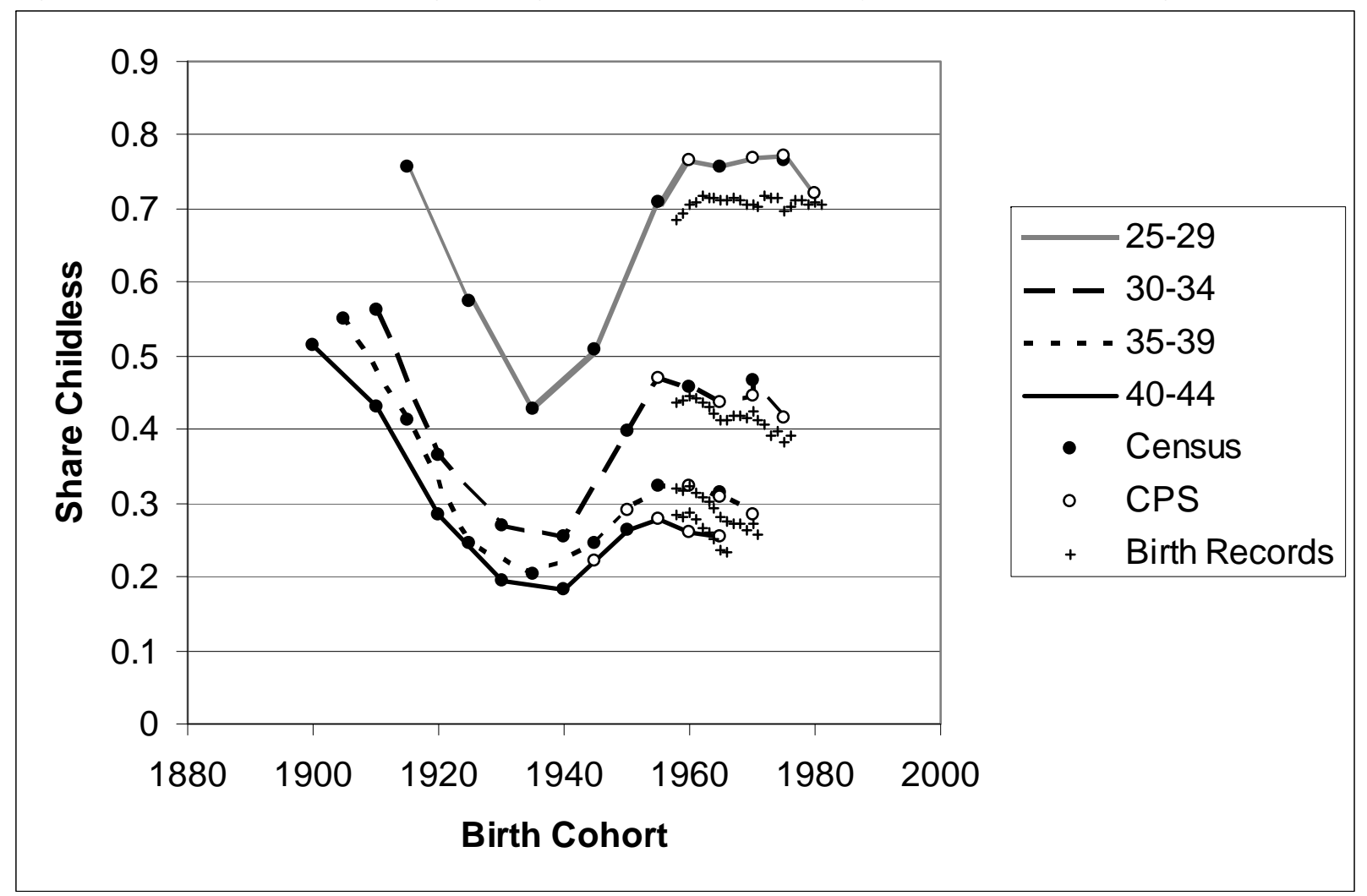

Note. Estimates for college graduate women from the 1940-2000 Censuses, the 1985, 1995, 2000, 2004, and 2006 June CPS, and the 1976-2006 Vital Statistics matched to the March CPS. Estimates shown for 5-year birth cohorts, with the birth years shown, giving the birth year of the youngest members of each cohort. 
Figure 3. Changes from the 1951-55 Cohort in the Mean Number of Children, by Age.

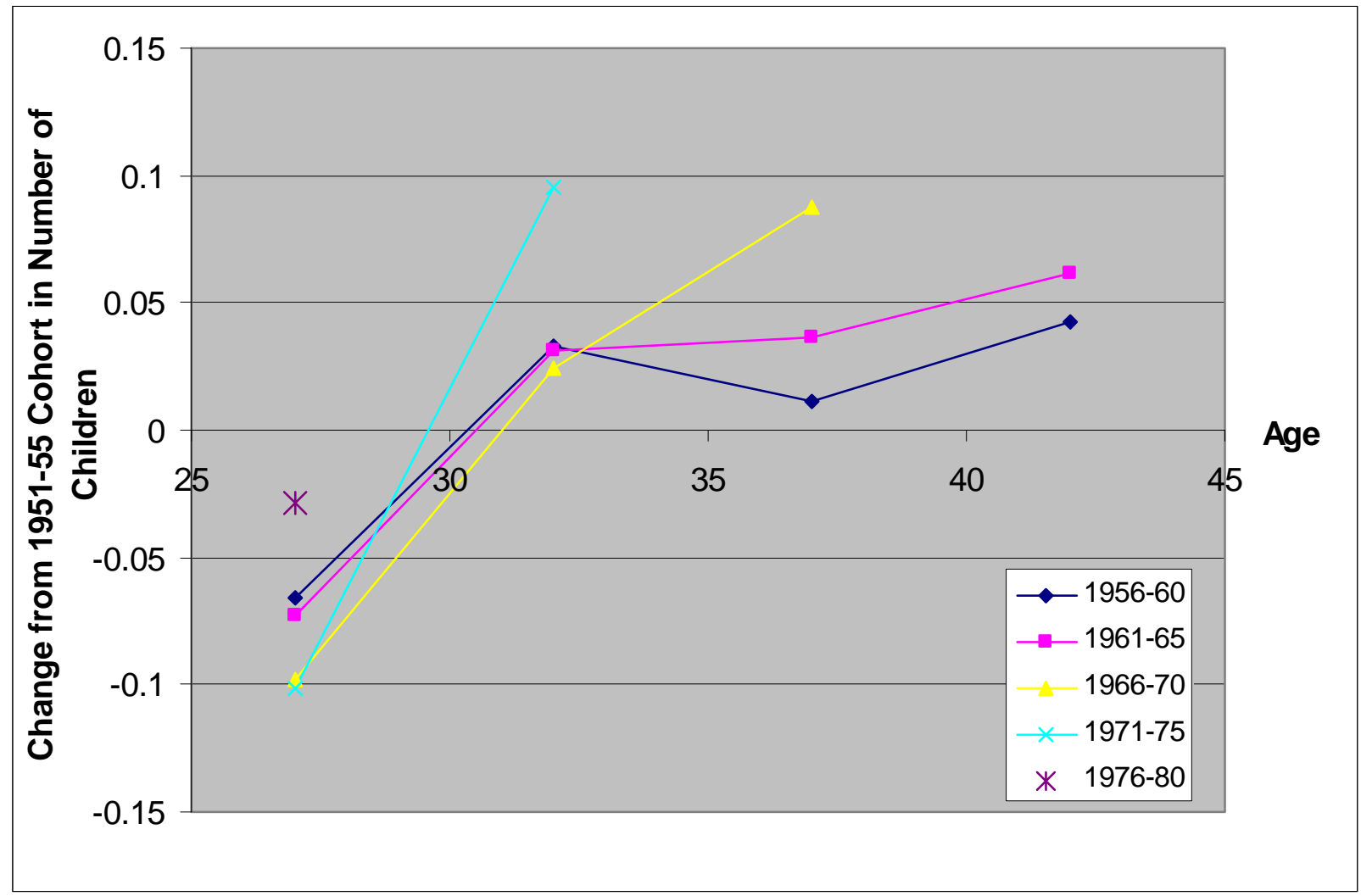

Note. Estimates of changes for 5-year birth cohorts from the 1980 and 1990 Census Micro-Samples and the 1985, 1995, 2000, and 2004/6 Current Population Surveys. The ages shown are the midpoints of 5year age ranges (i.e. 27 corresponds to the $25-29$ age group). Estimates are the difference in mean fertility between the cohort shown and the 1951-55 cohort reported in Table 3. 
Figure 4. Fertility Among College Graduate Woman, by Birth Cohort and Age.
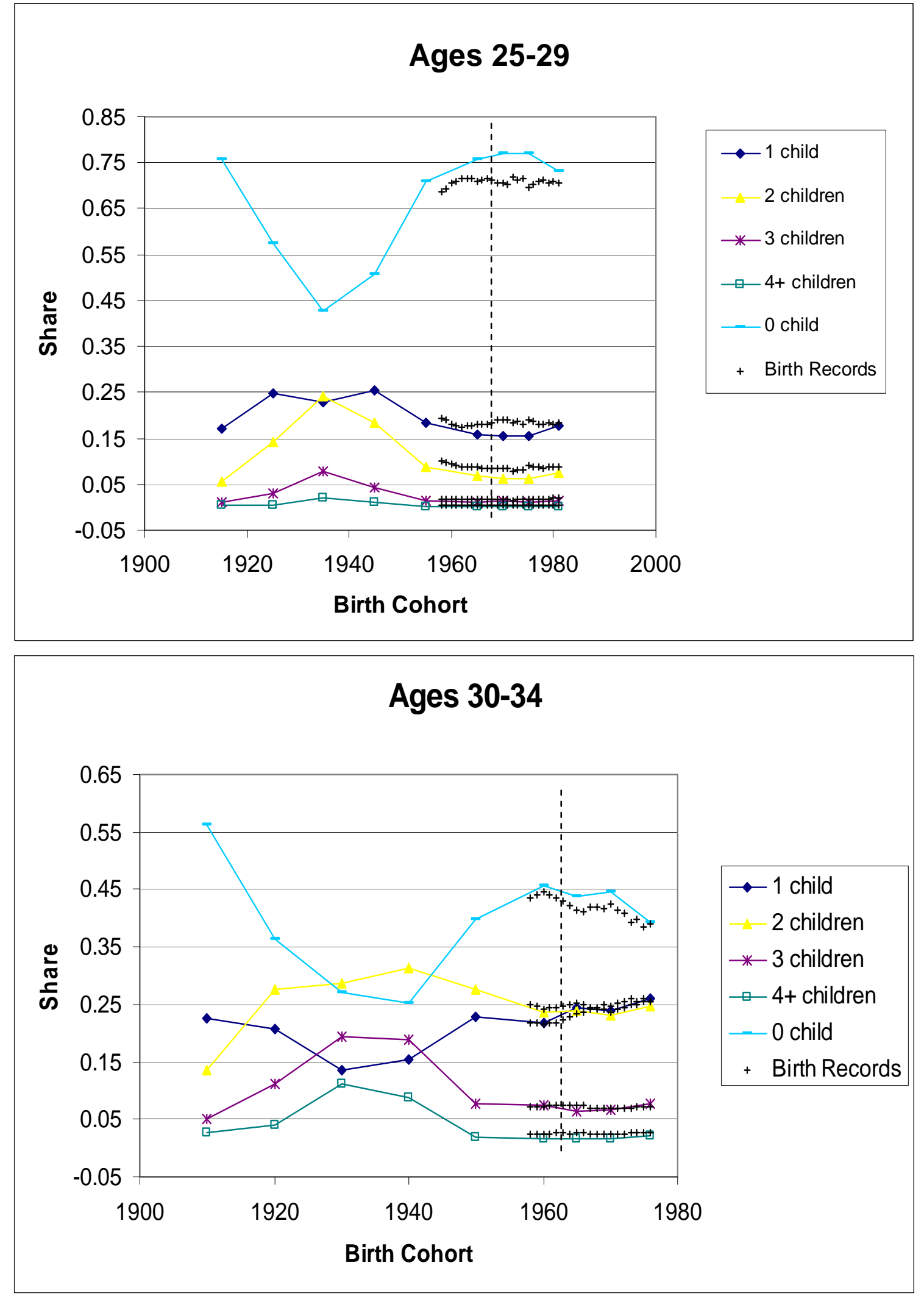

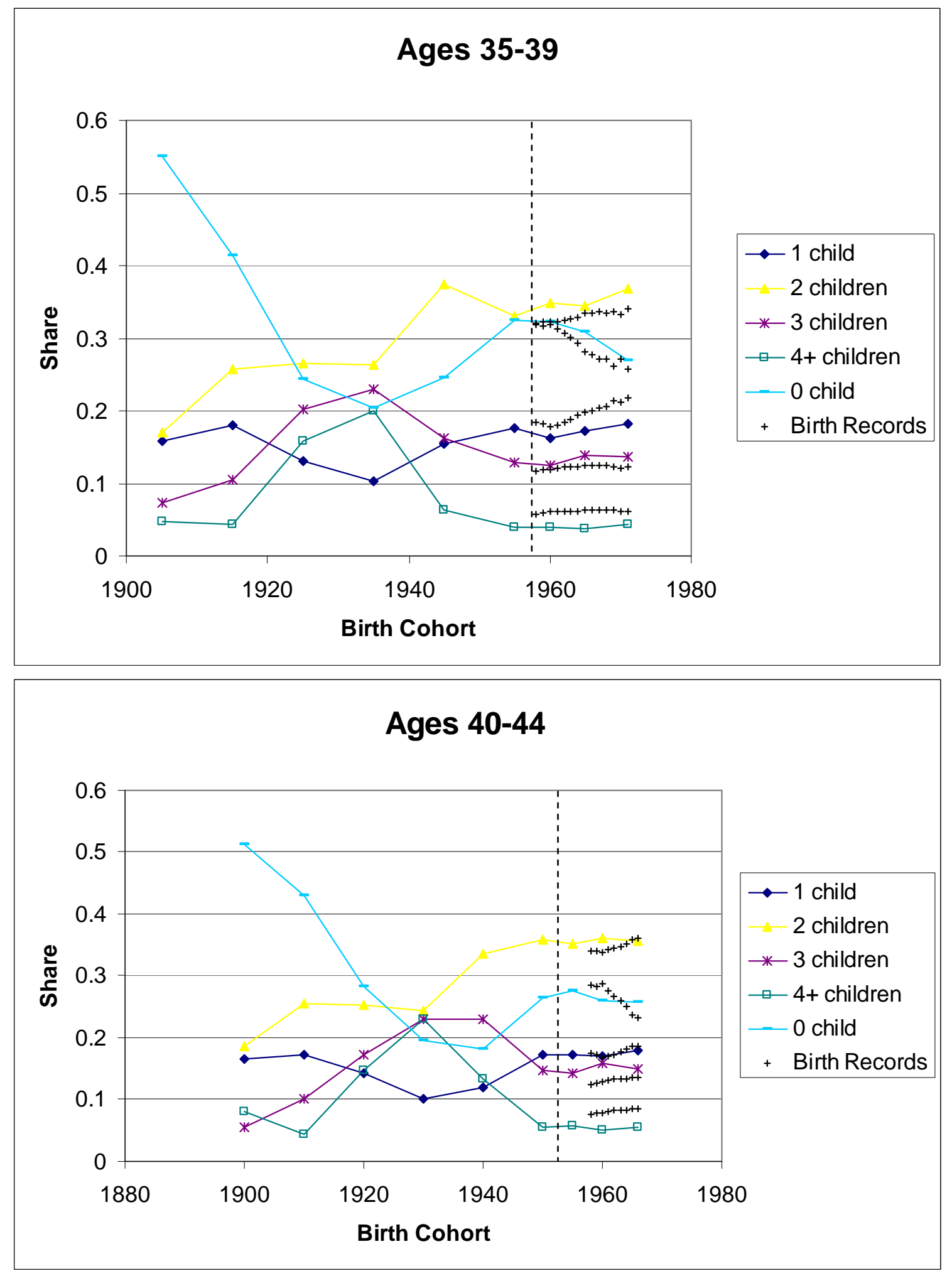

Note. Estimates for college graduate women from the 1940-90 Censuses (to the left of the vertical line), the 1995, 2000 and 2006 June CPS (to the right of the vertical line), and the 1976-2006 Vital Statistics matched to the March CPS. Estimates shown for 5-year birth cohorts, with the birth years shown, giving the birth year of the youngest members of each cohort. 
Figure 5. Plural Birth Rates for Children of College Graduate Women.

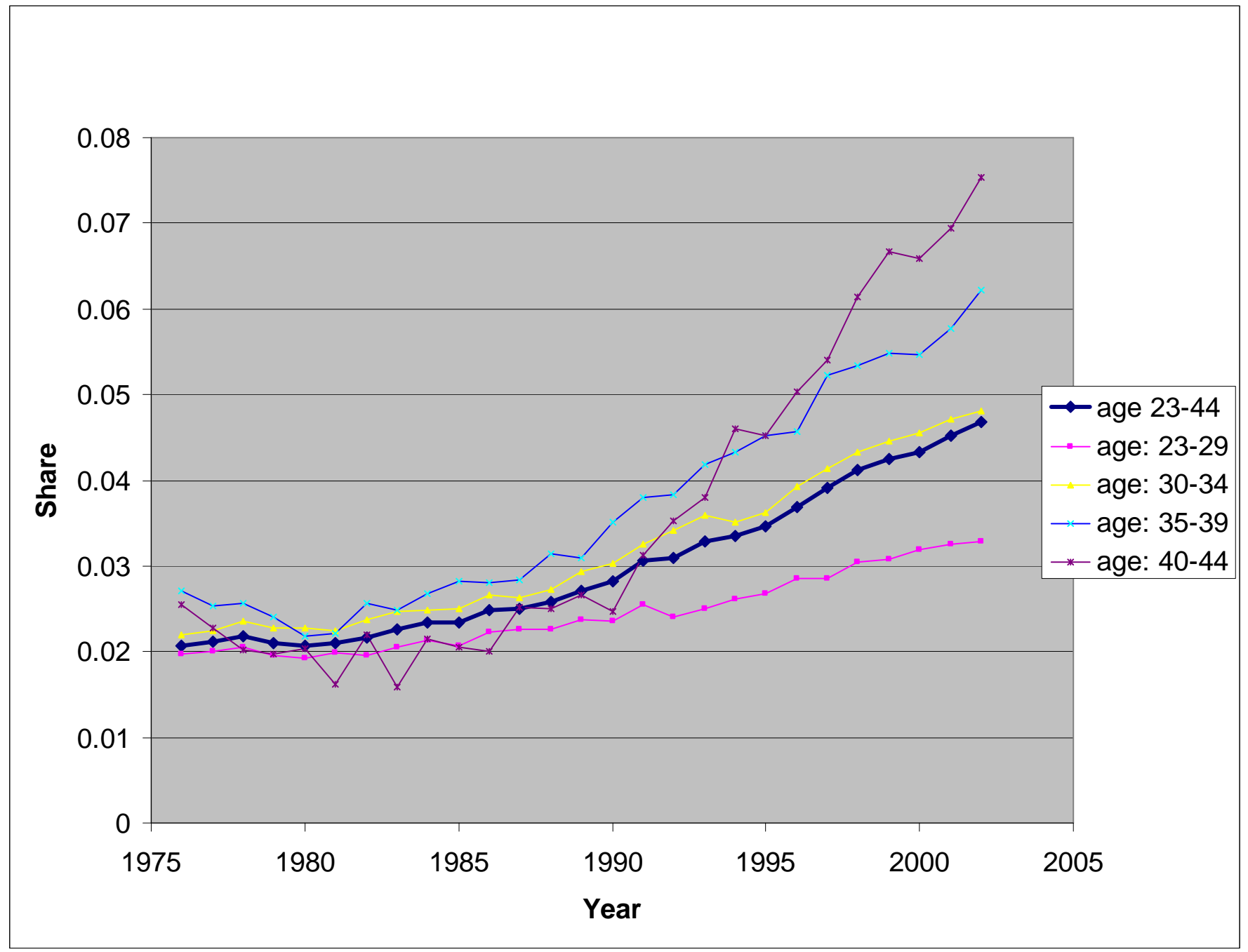

Note. Estimates from the Vital Statistics. The estimates are the share of children born in plural births. These results are based on the 46 states (excluding California, New Mexico, Texas and Washington State) for which education data are available in all years. 
Table 1: Childlessness and Marital Status for College Graduate Women: by Cohort and Age.

\begin{tabular}{lcccccc}
\hline & \multicolumn{3}{c}{ Percent Childless } & \multicolumn{3}{c}{ Percent Never Married } \\
\hline Cohort & $\begin{array}{c}\text { Ages 22- } \\
\text { 29 }\end{array}$ & Ages 30- & Ages 40- & Ages 22- & Ages 30- & Ages 40- \\
& 39 & 49 & 29 & 39 & 49 \\
\hline $1891-1900$ & & & 50.5 & & & 35.3 \\
$1901-10$ & & 55.6 & 45.6 & & 34.1 & 25.2 \\
$1911-20$ & 82.2 & 38.9 & 32.3 & 59.8 & 22.9 & 15.9 \\
$1921-30$ & 68.1 & 25.7 & 21.3 & 43.1 & 13.4 & 10.9 \\
$1931-40$ & 55.2 & 22.9 & 18.6 & 30.0 & 12.0 & 7.9 \\
$1941-50$ & 64.3 & 32.2 & 23.9 & 30.4 & 13.1 & 9.7 \\
$1951-60$ & 79.9 & 39.0 & $25.9^{* 1}$ & 46.9 & 18.9 & 11.6 \\
$1961-70$ & 83.1 & 39.1 & $25.7^{* 2}$ & 56.3 & 20.0 & 10.9 \\
$1971-80$ & 83.3 & $33.2^{* 3}$ & & 58.3 & $17.9^{* 3}$ & \\
\hline
\end{tabular}

Note. Estimates are from the US Census, except those denoted with an asterisk, which are from the June CPS. The CPS only asks about fertility until age 44, so these estimates only include women up to age 44 . For comparison, childlessness in the CPS in 2000 is roughly $1 \%$ lower than in the Census for women between 22 and 39. * 1 indicates women aged 40-44 in the 2000 CPS, who are from the 1956-60 cohort. (The percent childless for the women aged $40-44$ from the 1941-50 cohort in the 1990 Census is $26.4 \%$.) *2 indicates women who are 40-44 in the 2006 CPS who are from the 1962-66 cohort. *3 denotes women who are 30-39 in the 2006 CPS who are from the 1967-76 cohort. 
Table 2: Childlessness Among College Graduate Women since 1980.

\begin{tabular}{ccccc}
\hline Year & Ages 25-29 & Ages 30-34 & Ages 35-39 & Ages 40-44 \\
\hline 1980 (Census) & 70.9 & 39.9 & 24.6 & 18.2 \\
1985 & 76.4 & 46.8 & 28.9 & 22.0 \\
1990 (Census) & 75.7 & 45.6 & 32.4 & 26.4 \\
1995 & 76.8 & 43.7 & 32.3 & 27.7 \\
2000 & 77.1 & 44.6 & 30.9 & 25.9 \\
2004 & 71.6 & 45.2 & 28.3 & 24.8 \\
2006 & 73.1 & 39.4 & 27.0 & 25.7 \\
\hline
\end{tabular}

Note. Estimates are from the June CPS except 1980 and 1990, which are from the Census Micro-Samples. In the 2000 Census, childlessness is 76.0, 45.7, 30.5, and 31.7\% for the 4 age groups respectively (the last of which is likely biased upward as children leave home because the 2000 Census asks about children present). 
Table 3. Mean Number of Children by Age for Various Cohorts.

\begin{tabular}{lcccc}
\hline Cohort: & Ages 25-29 & Ages 30-34 & Ages 35-39 & Ages 40-44 \\
\hline $1951-55$ & $0.419^{*}$ & 0.950 & $1.399^{*}$ & 1.550 \\
$1956-60$ & 0.353 & $0.983^{*}$ & 1.410 & 1.593 \\
$1961-65$ & $0.346^{*}$ & 0.982 & 1.435 & 1.612 \\
$1966-70$ & 0.321 & 0.974 & 1.486 & \\
$1971-75$ & 0.318 & 1.045 & & \\
$1976-80$ & 0.390 & & & \\
\hline
\end{tabular}

Note. Estimates for 5-year birth cohorts from the 1980 and 1990 Census Micro-Samples (indicated by ${ }^{*}$ ) and the 1985, 1995, 2000, and 2004/6 Current Population Surveys. 
Table 4: Marital Status and Childlessness Among College Graduate Women since 1980.

\begin{tabular}{cccccc}
\hline & Year & Ages 25-29 & Ages 30-34 & Ages 35-39 & Ages 40-44 \\
\hline Percent & 1980 (Census) & 34.9 & 15.5 & 10.7 & 7.8 \\
Never & 1985 & 41.5 & 21.7 & 12.5 & 9.0 \\
Married & 1990 (Census) & 43.6 & 22.9 & 15.0 & 10.7 \\
& 1995 & 45.7 & 20.7 & 15.1 & 11.1 \\
& 2000 & 47.9 & 22.7 & 15.8 & 10.8 \\
& 2004 & 44.2 & 22.9 & 13.1 & 12.1 \\
& 2006 & 48.3 & 21.4 & 14.3 & 12.2 \\
\hline Percent & 1980 (Census) & 97.4 & 94.9 & 94.7 & 94.0 \\
Childless & 1985 & 97.5 & 94.4 & 95.3 & 98.7 \\
among & 1990 (Census) & 96.9 & 94.5 & 92.4 & 92.3 \\
Never- & 1995 & 96.6 & 91.4 & 94.1 & 92.9 \\
Married & 2000 & 96.9 & 92.0 & 93.0 & 93.1 \\
& 2004 & 91.7 & 90.4 & 90.1 & 91.1 \\
& 2006 & 91.0 & 88.7 & 88.8 & 85.8 \\
\hline Percent & 1980 (Census) & 58.0 & 29.9 & 16.3 & 11.8 \\
Childless & 1985 & 63.5 & 33.8 & 19.6 & 14.4 \\
among & 1990 (Census) & 60.8 & 31.3 & 21.8 & 18.6 \\
Married & 1995 & 61.7 & 31.8 & 21.4 & 19.6 \\
& 2000 & 60.7 & 31.1 & 19.3 & 17.9 \\
& 2004 & 56.3 & 31.9 & 18.8 & 15.8 \\
& 2006 & 59.4 & 26.1 & 16.7 & 17.4 \\
\hline
\end{tabular}

Note. Estimates are from the June CPS except 1980 and 1990, which are from the Census Micro-Samples. 
Table 5: Childlessness of Women, by Education Level since 1980.

\begin{tabular}{|c|c|c|c|c|c|}
\hline $\begin{array}{l}\text { Education } \\
\text { Level }\end{array}$ & Year & Ages 25-29 & Ages 30-34 & Ages 35-39 & Ages 40-44 \\
\hline High School & 1980 (Census) & 25.4 & 14.0 & 10.0 & 8.6 \\
\hline Graduates & 1985 & 31.8 & 19.2 & 12.0 & 9.5 \\
\hline \multirow[t]{5}{*}{ Exactly } & 1990 (Census) & 29.1 & 18.1 & 13.6 & 11.3 \\
\hline & 1995 & 27.2 & 18.3 & 14.9 & 13.1 \\
\hline & 2000 & 25.7 & 17.4 & 15.8 & 15.4 \\
\hline & 2004 & 26.8 & 16.9 & 13.9 & 17.0 \\
\hline & 2006 & 29.6 & 20.3 & 14.2 & 18.5 \\
\hline Some & 1980 (Census) & 43.8 & 22.3 & 14.2 & 9.9 \\
\hline \multirow[t]{6}{*}{ College } & 1985 & 44.5 & 27.5 & 16.3 & 12.1 \\
\hline & 1990 (Census) & 45.3 & 26.2 & 19.5 & 15.2 \\
\hline & 1995 & 44.5 & 26.8 & 19.6 & 15.6 \\
\hline & 2000 & 39.7 & 25.5 & 19.3 & 18.2 \\
\hline & 2004 & 40.7 & 21.9 & 18.9 & 18.1 \\
\hline & 2006 & 42.0 & 21.3 & 16.9 & 19.5 \\
\hline College & 1980 (Census) & 66.2 & 33.7 & 18.8 & 13.7 \\
\hline Graduates & 1985 & 74.0 & 43.4 & 25.0 & 18.1 \\
\hline \multirow[t]{5}{*}{ Exactly } & 1990 (Census) & 74.3 & 43.1 & 29.6 & 23.2 \\
\hline & 1995 & 75.0 & 41.3 & 30.4 & 26.8 \\
\hline & 2000 & 74.8 & 41.8 & 28.7 & 23.7 \\
\hline & 2004 & 69.2 & 43.1 & 26.8 & 24.6 \\
\hline & 2006 & 71.0 & 35.1 & 24.5 & 24.4 \\
\hline Graduate & 1980 (Census) & 78.8 & 47.5 & 31.5 & 23.7 \\
\hline \multirow[t]{6}{*}{ Education } & 1985 & 83.6 & 52.6 & 33.6 & 26.0 \\
\hline & 1990 (Census) & 81.7 & 52.7 & 38.0 & 31.5 \\
\hline & 1995 & 84.3 & 52.1 & 36.7 & 29.5 \\
\hline & 2000 & 84.1 & 51.9 & 36.7 & 31.6 \\
\hline & 2004 & 80.4 & 50.0 & 32.4 & 25.6 \\
\hline & 2006 & 79.0 & 48.5 & 31.8 & 28.4 \\
\hline
\end{tabular}

Note. Estimates are from the June CPS except 1980 and 1990, which are from the Census Micro-Samples. 
Table 6: Conditional Fertility Among College Graduate Women since 1980.

\begin{tabular}{ccccc}
\hline Year & Ages 25-29 & Ages 30-34 & Ages 35-39 & Ages 40-44 \\
\hline 1980 (Census) & 1.393 & 1.805 & 2.209 & 2.551 \\
1985 & 1.443 & 1.769 & 2.109 & 2.286 \\
1990 (Census) & 1.390 & 1.796 & 2.068 & 2.151 \\
1995 & 1.363 & 1.722 & 2.080 & 2.145 \\
2000 & 1.323 & 1.746 & 2.074 & 2.150 \\
2004 & 1.331 & 1.789 & 2.095 & 2.144 \\
2006 & 1.435 & 1.768 & 2.071 & 2.139 \\
\hline
\end{tabular}

Note. Estimates give the mean number of children for women having at least 1 child. Estimates are from the June CPS except 1980 and 1990, which are from the Census Micro-Samples. 
Appendix Table 1: Trends in Childlessness of College Graduate Women since 1980.

\begin{tabular}{cccccc}
\hline Year & Ages 25-44 & Ages 25-29 & Ages 30-34 & Ages 35-39 & Ages 40-44 \\
\hline 1980 (Census) & $-.0709^{* * *}$ & $-.0695^{* * * *}$ & $-.0552^{* * * *}$ & $-.0829^{* * *}$ & $-.0997^{* * *}$ \\
& $(.0080)$ & $(.0085)$ & $(.0196)$ & $(.0056)$ & $(.0173)$ \\
1985 & -.00957 & -.00724 & .0254 & -.0280 & $-.0513^{* *}$ \\
& $(.01153)$ & $(.01669)$ & $(.0245)$ & $(.0189)$ & $(.0225)$ \\
1990 (Census) & -.00308 & -.0124 & .0131 & -.00410 & -.0111 \\
& $(.00756)$ & $(.0082)$ & $(.0183)$ & $(.01038)$ & $(.0186)$ \\
1995 & 0 & 0 & 0 & 0 & 0 \\
2000 & & & & \\
& -.00368 & .00253 & .000557 & -.0100 & -.0119 \\
2002 & $(.00883)$ & $(.01149)$ & $(.020563)$ & $(.0124)$ & $(.0217)$ \\
& $-.0170^{*}$ & $-.0259^{*}$ & -.00778 & -.0180 & -.0224 \\
2004 & $(.0098)$ & $(.0140)$ & $(.02566)$ & $(.0121)$ & $(.0215)$ \\
& $-.0235^{* * *}$ & $-.0522^{* * *}$ & .0125 & $-.0416^{* * *}$ & -.0222 \\
& $(.0085)$ & $(.0109)$ & $(.0179)$ & $(.0118)$ & $(.0167)$ \\
& $-.0383^{* * *}$ & $-.0412^{* * *}$ & -.0569 & $-.0525^{* * * *}$ & -.00755 \\
& $(.0094)$ & $(.0132)$ & $(.0194)$ & $(.0113)$ & $(.0176)$ \\
\hline
\end{tabular}

Note. Estimates from linear regression models in which 1995 is the base year. Standard errors, which are clustered at the age-year level, reported in parentheses. Estimates control for schooling (among collegegraduates) and dummy variables for years of age (within categories) race (black or other), and Hispanic background. Statistical significance denoted by *** (1\%); ** (5\%), and * $(10 \%)$. 